\section{A Comparison of Previsits for Youth Field Trips to Public Gardens}

\author{
Cynthia Haynes ${ }^{1}$, Jon C. Pieper ${ }^{2}$, and Cary Trexler ${ }^{3}$
}

AdDitional INDEX wORDs. prequeing, Web education, novelty effect, pedagogy, youth education

\begin{abstract}
Summary. Creating effective learning experiences with limited educational resources has compelled educators to maximize the value of field trips. A common problem associated with field trips is anxiety felt by students in new surroundings, a situation that can distract students and adversely affect learning. Previsit activities before a field trip may reduce such anxiety and thereby increase attentiveness and learning. The objective of this study was to compare the effects of traditional and Internet-based previsit activities on learning and attitudes of fourth and fifth graders after a field trip to a public garden. Students in three classes were evaluated. Half of each class was assigned to one of the two previsit treatments. Three forms of assessments were used to measure the students' perceptions and learning: 1) observations were made to determine how many students remained on-task during the field trip, 2) 12 close-ended (Likert scale) questions were given to students and used to evaluate attitudinal responses the day after the field trip, and 3 ) seven open-ended questions were given to students and used to evaluate cognitive responses 1 week after the field trip. Attitudinal responses were identical between treatments. Observational data indicated that students subjected to the Internet-based previsit activity exhibited fewer off-task behaviors. Internet-based previsit activities increased cognitive scores in students compared to the traditional previsit activities for two of seven questions. The advantages of the Internet-based previsit activities may be the result of enhanced opportunity for self-directed learning and access to additional content.
\end{abstract}

$\mathrm{F}$ rom the earliest grades, students should experience science in an engaging form that fosters understanding (National Academy of Sciences, 1996). Early exposure to environmental concepts improves children's attitudes toward the natural sciences and the environment (Kahtz, 1995; Midden and Chambers, 2000; Skelly and Zajicek, 1998). Hancock and Farris (1988) suggested that outdoor education, when compared to indoor learning, improves understanding of the sciences by increasing general cognitive abilities, increasing student satisfaction, providing a physical connection to the sciences, and allowing a deeper understanding of tasks at hand.

One way teachers have exposed students to outdoor education is through the integration of school gardening into science curricula (DeMarco et al., 1999; Midden and Chambers, 2000). Unfortunately, not all schools or classrooms have the space,

Iowa State University, Ames, IA 50011.

${ }^{1}$ Assistant Professor, Department of Horticulture.

${ }^{2}$ Graduate Student, Department of Horticulture.

${ }^{3}$ Assistant Professor, Department of Agriculture Educa tion; currently at School of Education, University of California, Davis, CA 95616. time, or budget to create such gardens. Therefore, schools often rely on field trips to public gardens as a means of providing students with outdoor educational opportunities.

Field trips to gardens influence how children perceive the environment (Kahtz, 1995; Midden and Chambers, 2000; Skelly and Zajicek, 1998). Also, field trips improve understanding of difficult concepts by emphasizing participatory activities (Gagne, 1970; Wright, 1980). Field trips, however, are usually limited by time and budget, are difficult to organize, and can create a level of anxiety in students and teachers that hinders learning.

Familiarity with a setting can affect learning during field trips (Falk et al., 1978; Gennaro, 1981; Gennaro et al., 1982; Kubota and Olstad, 1991; Stronck, 1983). Falk et al. (1978) proposed that an unfamiliar setting might decrease a child's ability to learn. Likewise, Wiesler and McCall (1976) found that novel stimuli cause distractions that increase the time students take to focus on learning or accomplishing tasks. Children adjust to novel settings by focusing on the new environment first, hampering learning during the adjustment period. On the other hand, Kubota and Olstad (1991) and Prather
(1989) suggested that novel environments foster an exploratory attitude in children that aids learning. Falk and Balling (1982) and Martin et al. (1981) found that children exposed to a novel environment gained significant knowledge of outdoor settings and non-task portions of a field trip.

While there are conflicting conclusions on the impact of a new environment on learning, Koran et al. (1983) and Gennaro (1981) showed that linking classroom activities to field trips increased cognitive learning and had a positive affect on attitudinal development. Reports have suggested that previsit activities - defined as the exposure of students to organized or designed curricular materials before a learning experience-can foster learning (Falk et al., 1978; Gennaro, 1981; Gennaro et al., 1982). Previsit activities, however, can be expensive and time-consuming. They may require additional resources such as books, speakers to talk about the subject, and reorganization of timetables and routines.

As teachers look for simple and inexpensive ways to conduct effective field trips, the design of previsit activities is an important factor to consider. In this regard, the Internet is an effective resource for learning that is available to most schools. Educational opportunities presented through computer-based technology increase every year (Jones and Paolucci, 1999). This virtual environment provides almost infinite features to teach and interact with the online student, including discussion boards, file transfers, interactive displays, and libraries of information. Kulik et al. (1985) conducted a meta-analysis of 28 studies involving computer-assisted instruction. All except five studies showed an increase in the achievement scores of students in computer-based instruction classes compared to traditional classes.

As public gardens continually search for new ways to develop and increase participation in their educational programs (Byers, 1999), the integration of computer-based learning and the field trips could prove to be an important tool for educators to connect children to the natural sciences and outdoor environment. Online experiences could be used to deliver previsit activities that reduce the "novelty effect" with a minimal cost per student. It is not known, however, if Internet-based previsits are as effec- 
tive as more traditional methods, such as speaker visits. In addition, public gardens have just begun to introduce online experiences that involve more than pages of text and pictures. Many gardens have been slow to provide computer-based experiences that implement interactivity, discussions, and concepts aimed at children.

The purpose of this study was to compare the effects of Internet-based and traditional previsit activities on student learning and attitudinal development in the context of a field trip to a public garden.

\section{Materials and methods}

The field trip was conducted in the Children's Garden at Iowa State University's Reiman Gardens in Ames. Since 2001, the Children's Garden has been a destination for organized school field trips with an "Iowa" theme teaching science and Iowa history. Garden features include a corncrib, a covered bridge, and a sod home. The educational programming at Reiman Gardens offers workshops and plant labs that teach youth about nature through activities, crafts, stories, and shows. The educational program used in this study included the following topics: 1) how early settlers lived in Iowa, 2) exhibits about grasses, 3 ) descriptions of sod homes, and 4) educational games about grasses. The program also included an interactive web site describing the history of pioneers and the science and importance of grasses.
To ensure that the learning environment at Reiman Gardens was new to students, classes in Des Moines Independent school district and North East Hamilton Community school district in Blairsburg were selected, rather than local classes in Ames. Only two students in the study indicated that they had visited the gardens. Two fourth grade classes and one fifth grade class participated in field trips to Reiman Gardens in early May 2002, totaling 52 students. These classes and grade levels were selected based on each school district's curriculum calendar to coordinate with the Iowa history unit.

The researchers visited participating teachers and confirmed that the participating classes' coursework three months prior to the previsit lessons did not include sod houses or biology of grasses. Additionally, the teachers agreed to refrain from teaching those subjects or other subjects related to Iowa history 3 weeks before and 1 week after the field trip to further limit students' exposure.

The researchers visited each classroom I week before the students' visit to Reiman Gardens. Each of the three classes was randomly split into two treatment groups with either traditional (lecture-based) or Internetbased, previsit activities. To control the influence of the teachers, an outside instructor delivered previsit activities for each treatment. Instructional procedures for the previsit activities were identical for each of the three class- rooms and lasted for approximately $50 \mathrm{~min}$. Although the previsit activities differed in delivery method, both designed to cover the same concepts and content as would be encountered on the field trip. The difference was the manner of presentation to the students and interaction between instructor and class. Immediately after the field trips, post-assessments and administration instructions were provided to teachers for their students.

The previsit activities involved a grass identification activity and a vocabulary activity. The traditional previsit consisted of a speaker who discussed the material and helped with grass identification activities. The activities included a drawing of a grass plant depicting the parts of the plant. Students colored the drawing as the speaker helped them identify and discuss each grass part. The Internet-based previsit activity consisted of selecting parts of a grass picture with accompanying text describing individual parts.

For the vocabulary activity, the traditional previsit consisted of a word jumble during which students discussed the relation of the words to the subject matter with the speaker. Using word content and ideas similar to the traditional previsit, the Internet-based previsit word identification involved a game that asked questions about what students had learned on the web page. Table 1 briefly summarizes and compares the previsit activities used for each treatment.

Table 1. Descriptions of previsit activities for two fourth grade classes and one fifth grade class before a field trip to a public garden.

\begin{tabular}{|c|c|}
\hline Traditional previsit & Internet previsit \\
\hline $\begin{array}{l}\text { Introduction } \\
\text { Questions pertaining to what they know and how they feel } \\
\text { about the field trip }\end{array}$ & $\begin{array}{l}\text { Introduction } \\
\text { Questions pertaining to what they know and how they feel } \\
\text { about the field trip }\end{array}$ \\
\hline $\begin{array}{l}\text { Grass coloring sheet } \\
\text { Identify parts of the grass by coloring a worksheet } \\
\text { Discuss function of each part of the grass plant with lecturer } \\
\text { Vocabulary } \\
\text { Discuss vocabulary relating to science of grasses } \\
\text { Find new words in word jumble/worksheet } \\
\text { Pictures } \\
\text { Exhibit images via overhead of Reiman Gardens including: } \\
\text { entrance, paths, buildings, and children's garden } \\
\text { Rules and safety } \\
\text { Discuss rules of the garden }\end{array}$ & $\begin{array}{l}\text { Web site } \\
\text { Identify parts of the grass by selecting parts of a grass picture } \\
\text { Identify function of each part of the grass plant by selecting it } \\
\text { and learning about it with a combination of text and images } \\
\text { Learn the differences in grass varieties through comparison } \\
\text { of images of grasses found at Reiman Gardens } \\
\text { Descriptions and images of what a sod house is, why it was } \\
\text { built, and how it was built by settlers of Iowa } \\
\text { Vocabulary } \\
\text { Puzzle game emphasizing vocabulary of the information } \\
\text { presented on the website } \\
\text { Links to web pages containing images and descriptions } \\
\text { of sites similar to those used in traditional previsit } \\
\text { Rules and safety } \\
\text { Link to web page describing rules of the garden }\end{array}$ \\
\hline
\end{tabular}


The field trip to Reiman Gardens, designed by Gross (2002), focused on the science of grasses and the history of sod homes in Iowa. All students were given the same field trip, which included indoor activities such as exhibits of the diversity of grasses, displays of how grasses grow and what grasses provide, and games with grass products in daily consumption. Outdoor activities involved exploring the sod house, building a sod home with carpet squares, and listening to a story about Iowa pioneers and their sod homes.

To assess student learning, openended assessments were given to the classes 1 week after the field trip. An elementary science education professor at Iowa State University confirmed the validity of this assessment. The openended assessments consisted of seven compound questions that were given values of 0 to 2 points each. Partial points were given for incomplete answers. The use of open-ended questions encouraged students to think of answers and elicited a wide range of responses that may have been limited in a closed-ended model (Shoemaker et al., 2000).

To assess attitudinal responses, a quantitative assessment consisting of 12 questions based on a Likert scale (1 to 5), and three open-ended questions were given one day after the field trip. A high score of 4 or 5 for each question was considered a positive or agreeable response, where a 1 or 2 was negative or less agreeable.

Visual observations were recorded during the field trips at both indoor and outdoor learning stations. Important information such as face validity (reactions to the environment through facial expressions), attentiveness, focus, and attitudes toward the environment can be gained from observing individuals in the actual setting (Shoemaker et al., 2000). Such observations of the actions and reactions of students also can allow the researcher to identify and document any odd or interesting incidents (Hammersly, 1990). The focus of these observations was to determine how many students remained attentive and on-task during each activity. An off-task behavior was defined as an activity or motion by a student during the time at a learning station that was not oriented to the educational task at hand. Examples of such off-task activities included: students using a magnifying lens for purposes other than looking at the grass specimens, discussions about subjects not regarding field trip activities, playing in the gravel, etc. Two graduate students, previously trained to observe youth, observed the students during the field trips and recorded the incidences of off task behaviors. Every instance of inattentiveness noticed by the observer was recorded during the field trip. Neither observer participated in any activities or interacted with the students. Students were video taped to allow further review of any incidents or behaviors missed by the observers.

Scores for cognitive and attitudinal assessments were analyzed using SAS 8.1 statistical software (SAS Institute, Inc., Cary, N.C.). Cognitive scores were analyzed with the $t$-test, means, and variances procedures of SAS. The $t$ test procedure used the pooled method for equal variances and the Satterthwaite method for unequal variances. Attitudinal scores were also analyzed using the means procedure, but differed by the use of Fisher's exact test in determining significant differences between groups of scores.

\section{Results}

Student Learning. Students from the internet previsit treatment scored significantly higher (at the 90\% confidence level) on tests compared to those from the traditional previsit treatment. The results showed that for five of the seven open-ended questions, there was no significant difference in test scores for student learning between the Internet-based and traditional previsit treatments. For Question 3, "Describe three bad things about living in a sod home," and Question 4, "Describe why sod was a good building material" the Internet-based previsit activity resulted in a significantly higher test score than the traditional previsit activity. (Table 2 ).

Attitudinal response. The total scores for all the closed-ended questions showed no significant differences for attitudinal responses between the Internet-based and traditional previsit treatments (Table 3 ). Inspection of the scores in Table 3 generally show the attitudinal responses of students to the field trip and activities. For example, students were not nervous about visiting the garden (i.e., Question 4, Table $3)$. They did not feel that they learned the most about grasses through their previsit activities. Students also believed that they understood where to go at the beginning of the tour, knew

Table 2. Test scores from a cognitive assessment of fourth and fifth grade students subjected to Internet or traditional previsit activities before a field trip to a public garden. Data were derived from answers to a questionnaire which had seven open-ended questions and was completed 1 week after the field trip. The scores are averages from 26 students for each previsit activity.

\begin{tabular}{llcc}
\hline Question & $\begin{array}{c}\text { Previsit } \\
\text { activity }\end{array}$ & $\begin{array}{c}\text { Possible } \\
\text { score }\end{array}$ & Score \\
\hline 1. Why did Iowans build sod homes? & Internet & 2 & 1.44 \\
& Traditional & 2 & 1.37
\end{tabular}

2. Describe three good things about living in a sod home.

$\begin{array}{lll}\text { Internet } & 6 & 4.41 \\ \text { Traditional } & 6 & 3.82\end{array}$

3. Describe three bad things about living in a sod home.

4. Describe why sod was a good building material

$\begin{array}{lll}\text { Internet } & 6 & 5.85^{\star * *} \\ \text { Traditional } & 6 & 4.22 \\ \text { Internet } & 2 & 1.78^{\star \star} \\ \text { Traditional } & 2 & 1.33\end{array}$

5. How are prairie grasses different from other plants?

6. How are grasses used by people today?

Internet $\quad 2 \quad 0.78$

Traditional $2 \quad 0.93$

7. Draw and label the parts of a grass plant.

$\begin{array}{lll}\text { Internet } & 2 & 1.15 \\ \text { Traditional } & 2 & 1.37\end{array}$

Internet $\quad 4 \quad 2.44$

Total of all questions

Traditional $4 \quad 2.59$

Internet $24 \quad 17.85^{\star}$

Traditional $24 \quad 15.63$

\footnotetext{
**,** Significant via $t$ test analysis at $P<0.10,0.05$, or 0.001 , respectively.
} 
Table 3. Average test scores from an attitudinal assessment of fourth and fifth grade students subjected to Internet or traditional previsit activities before a field trip to a public garden. Data were derived from answers to a questionnaire that was completed after the field trip. The questionnaire consisted of 12 closed-ended questions on a Likert scale of 1 to 5 , where $1=$ negative reaction and $5=$ positive reaction. The scores are averages from 26 students for each previsit activity.

Question

1. I understood where I was to go at the beginning of the tour.

2. I understood what the rules of the garden were.

3. I understood why we went to the garden

4. I was nervous about going to the garden.

5. I had fun at Reiman Gardens.

6. I had fun touching the grasses.

7. I was interested in visiting the garden.

8. I know more about sod houses than before the field trip.

9. I learned the most about grasses online.

9. I learned the most about grasses with the word jumble.

10. I learned by sitting in the sod house.

11. I learned by building a sod house wall.

12. I learned by touching different grasses

Previsit

activity

Test

Internet

3.828

Traditional 4.615

Internet $\quad 4.759$

Traditional 4.615

Internet $\quad 4.483$

Traditional 4.462

Internet $\quad 1.828$

Traditional $\quad 1.423$

Internet $\quad 4.552$

Traditional 4.346

Internet $\quad 3.379$

Traditional 3.885

Internet $\quad 4.207$

Traditional 4.346

Internet $\quad 3.828$

Traditional 3.462

Internet $\quad 2.828$

Traditional 2.885

Internet $\quad 3.517$

Traditional 3.769

Internet $\quad 3.966$

Traditional 4.077

Internet $\quad 3.379$

Traditional

3.731

${ }^{*},{ }^{* *},{ }^{* * *}$ Significant via $t$ test analysis at $P<0.10,0.05$, or 0.001 , respectively.

the rules of the garden, understood why they went to the garden, were interested in visiting the garden, and had fun at Reiman Gardens.

Three open-ended questions were used to further assess students' overall attitude towards the field trip. While these responses varied considerably and were not amenable to quantitation, they did provide additional perspective. The first of these questions, "When I made the sod man I learned...?", indicated that all students felt they had learned how to grow, care for, and identify parts of grasses. Students were also asked what they enjoyed the most and least about the field trip. When asked what they enjoyed the most, many students of both previsit treatments indicated that they most enjoyed making the sod man, playing with the frog pumps and building the sod house wall with carpet squares. When asked what they enjoyed the least, many students disliked touching live grass, building the sod house wall, or disliked nothing. Building the sod wall elicited the most responses and students were equally split on expressing like or dislike of this activity.

OBSERVATIONS OF OFF-TASK BEHAVIORS. To further evaluate attitudinal responses, results from visual observations of students were compiled into their appropriate treatment groups (or assigned treatment group). Students given the Internet-based previsits were observed to be on-task more often in both the indoor and outdoor learning activities. However, all students engaging in outdoor activities were more likely to exhibit an off-task behavior during a learning activity compared to indoor activities (Table 4 ).

\section{Discussion}

The Internet-based and traditional previsit activities used in this study were distinct treatments. For example, the Internet allowed students to explore and learn at their own pace, whereas the pace of the tradi- tional previsit was determined by the teacher's style of delivering the subject matter. The Internet provided an opportunity to access more information in the allotted time period than the teacher could deliver in the traditional classroom setting. For example, the Internet provided many more visuals and informational displays that were not part of the traditional previsits. The self-directed aspect of Internet previsits also may have allowed students to learn what they thought was most interesting about the subjects. Observations made during the previsits showed that students not only studied the original sod house web page, but they also expanded their learning environment by following links to other web pages of similar content. Many students in the Internet previsit lessons also asked if they could visit the web site later to see what they missed. Conversely, self-directed learning may have caused students to visit sites not pertaining to the target educational material or to skip relevant target material that was not of interest to the student. In the traditional previsit, identifying, coloring, and games directed by the teacher had the advantage of keeping the students on task and oriented to the subject being taught.

This study showed that the Internet previsit activity resulted in more learning than the traditional previsit for some of the tested information (Table 2). This may have been due to the Internet treatment having the opportunity to access enhanced or more detailed content, or to spend more time in certain subject matters compared to the traditional treatment.

No difference in attitudinal responses was found between the Internet and traditional previsit treatments. The students' general attitudinal

Table 4. Number of incidents in which fourth and fifth grade students subjected to Internet or traditional previsit activities before a field trip students exhibited off-task behaviors during indoor and outdoor activities of the field trip to a public garden.

\begin{tabular}{llc}
\hline Setting & Treatment & $\begin{array}{c}\text { No. of } \\
\text { off-task } \\
\text { incidents }\end{array}$ \\
\hline Indoor & Internet & 6 \\
& Traditional & 14 \\
Outdoor & Internet & 27 \\
& Traditional & 42 \\
\hline
\end{tabular}


responses towards the field trip and activities were positive. Importantly, students were not nervous about going to the garden. The open-ended questions identified an activity (building the sod wall) that elicited a strong, but varied response. It would be of interest in future studies to analyze the relationship between such activities and learning.

Observational data pointed to a large gap of off-task incidents between Internet and traditional previsit treatments as well as between indoor and outdoor activities. It is possible that the Internet-based previsit activities provided content that allowed students to become more familiar with the field trip surroundings. The large difference in off-task incidents between indoor and outdoor activities may be related to the novelty effect. Students in a stimulus-rich and novel environment, such as a field trip to an outdoor garden, may become distracted from the proscribed tasks at hand.

\section{Conclusions}

Results from previous studies have shown positive effects of computerbased learning. Moore and Karabenick (1992) found that computer-based learning increased writing and reading skills of fifth grade students. A meta-analysis of 254 studies involving computer-based instruction showed that such programs typically produced positive results in raising examination scores and creating a positive attitude toward teaching and computers (Kulik and Kulik, 1991). Consistent with these findings, the current study showed that Internet-based, previsit activities were equal or superior to traditional activities for maximizing learning from a field trip. Therefore, educational web sites are a potentially cost-effective alternative to enhance student learning on field-trips.

The quality and style of Internet-based information are important aspects to be considered for future research in the area of preparatory activities before field trips. The current state of Internet-based learning environments is characterized by considerable variation in the quality and consistency of the educational value of the material (Mioduser et al., 2000). Further research should focus not only on the effectiveness of Internet-based education compared to traditional methods, but also on the relative ef- fectiveness of different Internet-based activities. We also suggest that the integration of cognitive, attitudinal, and observational evaluation criteria that were used in this study may be useful in establishing a more comprehensive perspective on the outcomes of field trips and previsit activities.

\section{Literature cited}

Byers, R. 1999. Reaching out: A university botanical garden builds long-distance relationships. HortTechnology 9(4):573-576.

DeMarco, L., D. Relf, and A. McDaniel. 1999. Integrating gardening into the elementary school curriculum. Hort Technology 9(2):276-281.

Falk, J.H., W.W. Martin, and J.D. Balling. 1978. The novel field-trip phenomenon: Adjustments to novel settings interferes with task learning. J. Res. Sci. Teaching 15(2):127-134

Falk, J.H. and J.D. Balling. 1982. The field trip milieu: Learning and behavior as a function of contextual events. J. Educ. Res. 76(1):22-28.

Gagne, R.N. 1970. The conditions of learning, 2nd ed. Holt, Rinehart, and Winston, New York.

Gennaro, E.D. 1981. The effectiveness of using previsit instructional materials on learning for a museum field trip experience. J. Res. Sci.Teaching 18(3):275-279.

Gennaro, E., S.A. Stoneberg, and S. Tanck. 1982. Chance or the prepared mind? J. Museum Educ. 7(4):16-18.

Gross, S.J. 2002. Evaluating the educational impact of pre- and post-visit activities on elementary students following a field trip to a public garden. Master Thesis, Iowa State Univ., Ames.

Hammersly, M. 1990. Classroom ethnography: Empirical and methodological essays. Open Univ. Press, Philadelphia.

Hancock, M. and P. Farris. 1988. Nurturing intellectual and personal growth through outdoor education. Delta Kappa Gamma Bul. 54(3):47-51.

Jones, T. and R. Paolucci. 1999. Research framework and dimensions for evaluating the effectiveness of educational technology systems on learning outcomes. J. Res. Computing Educ. 32(1):17-26.

Kahtz, A. 1995. Impact of environmental education classes at Missouri Botanical Garden on attitude and knowledge change of elementary school children. Hort Technology 5(4):338-340.

Koran, J.J. Jr., J.R. Lehman, L.D. Shafer, and M.L. Koran. 1983. The relative effects of pre- and post attention directing devices on learning from a "walk-through" museum exhibit. J. Res. Sci. Teaching 20:341-346.

Kubota, C.A. and R.G. Olstad. 1991. Effects of novelty reducing preparation on exploratory behavior and cognitive learning in a science museum setting. J. Res. Sci. Teaching 28(3):225-234.

Kulik, C.C. and J.A. Kulik. 1991. Effectiveness of computer-based instructions: An updated analysis. Computers Human Behavior 7:75-94.

Kulik, J.A., C.C. Kulik, and R.L. BangertDrowns. 1985. Effectiveness of computerbased education in elementary schools. Computers Human Behavior 1:59-74.

Martin, W.W., J.H. Falk, and J.D. Balling. 1981. Environmental effects of learning: The outdoor field trip. Sci. Educ. 65(3):301-309.

Midden, K.S. and J. Chambers. 2000. An evaluation of a children's garden in developing a greater sensitivity of the environment in preschool children. Hort Technology 10(2):385-390.

Mioduser, D., R. Nachmias, O. Lahav, and A. Oren. 2000. Web-based learning environments: Current pedagogical and technological state. J. Res. Computing Educ. 33(1):55-76.

Moore, M.A. and S.A. Karabenick. 1992. The effects of computer communications on the reading and writing performance of fifth-grade students. Computers Human Behavior 8:27-38.

National Academy of Sciences. 1996. National science education standards. Natl. Academy Press, Washington, D.C.

Prather, J.P. 1989. Review of the value of field trips in science instruction. J. Elementary Sci. Educ. 1(1):10-17.

Shoemaker, C.A., P.D. Relf, and V.I. Lohr. 2000. Social science methodologies for studying individuals responses in human issues in horticulture research. HortTechnology 10(1):87-93.

Skelly, S.M. and J.M. Zajicek. 1998. The effect of an interdisciplinary garden program on the environmental attitudes of elementary school students. HortTechnology 8(4):579-583.

Stronck, D.R. 1983. The comparative effects of different museum tours on children's attitudes and learning. J. Res. Sci. Teaching 20(4):283-290.

Weisler, A. and R.B. McCall. 1976. Exploration and play, resume and redirection. Amer. Psychologist July:492-504.

Wright, E.L. 1980. Analysis of the effect of a museum experience on the biology achievement of sixth-graders. J. Res. Sci. Teaching 17(2):99-104. 